\title{
Interlinking the effect of thermal mass and temperature control strategies in dwellings
}

\author{
Stijn Verbeke ${ }^{1,2,3}$, Amaryllis Audenaert ${ }^{1}$, Ivan Verhaert $^{1}$ \\ ${ }^{1}$ University of Antwerp, Energy and Materials in Infrastructure and Buildings (EMIB), Antwerp, Belgium \\ ${ }^{2}$ Unit Smart Energy and Built Environment, Flemish Institute for Technical Research (VITO), Boeretang 200, B-2400, Mol, Belgium \\ ${ }^{3}$ Building and Districts Energy Assessment, EnergyVille, Thor Park 8310, B-3600, Genk, Belgium
}

\begin{abstract}
Exposed heavyweight constructions with a high specific heat capacity can dampen and delay transient heat flows in buildings. This paper explores the dynamic effects of various construction assemblies and explores the effect of different temperature control strategies in relation to the thermal mass. The thermal inertia of a building not only affects the pace of heating up a thermal zone, but also the temperature set-back that can be attained with an intermittent heating regime, and thus the setpoints of control regimes. Based on a simulation study, it is demonstrated that the impact of the thermal mass on the heating demand of dwellings is rather limited in a temperate climate. Lightweight timber frame construction can display an annual heating energy demand of up to $6.6 \%$ higher compared to a heavy mass concrete and limestone construction in case of fixed thermostat setpoints. If a different control strategy with a highly intermittent thermostat schedule is implemented, the energy use of the lightweight construction can conversely have a lower heating energy expenditure, with a reduction of up to $-4.5 \%$. Modelling assumptions on the HVAC system capacity, the timing of the start-up moment of intermittent heating and the type of thermostat control - either based on air temperature or operative temperature - can have a significant influence on the simulation outcomes. Depending on the modelling assumptions and temperature control strategies implemented, the detailed dynamic simulations display that heavy mass buildings will not necessarily yield a lower heating demand as would be predicted by simplified monthly quasi-steady state calculations. In general, it is advocated that a better understanding of control strategies and resulting comfort sensations is required in building design and performance simulation.
\end{abstract}

\section{Introduction}

Improving the energy performance of buildings has become a major societal challenge due to economic, political and ecological motives. For domestic buildings in a heating dominated climate, thermal insulation of the building envelope, heat-recovery or demand controlled ventilation and the production efficiency of the heat generator are common energy efficiency measures. In a 'climate-responsive' design strategy, the building designer also explicitly takes into account solar gains and massing of the building to obtain an optimal thermal comfort and low energy demand.

Sometimes, the inclusion of high amount of accessible thermal mass of the building materials is also advocated as an effective energy saving measure for passive or low energy buildings [1]. In a transient situation, the thermal mass of a building can absorb, store and progressively release heat depending on the temperature difference with the immediate surroundings. As a consequence, buildings which contain large amounts of thermal capacity within the thermal envelope are able to dampen temperature fluctuations, an effect referred to as 'thermal inertia'. During a hot summer day, a high thermal inertia of the construction can result in slower warming up of the thermal mass inside the building envelope and consequently a reduced overheating risk. Thermal mass is also often believed to have a positive effect on reducing heating energy demand. The exposed thermal mass of a construction can store heat gains from the sun or from internal gains and release the stored energy later, thus reducing the additional heat input required then. In a building which exhibits less thermal inertia, gains might lead to a rise in indoor surface and air temperature, which results in higher transmission and ventilation losses, hence a slightly elevated heating energy demand later on, compared to a heavy mass equivalent.

Thermal mass of constructions can however also have potential negative impacts on the (energy) performance of a building. Constructions with extensive amounts of thermal mass might require more time to reach the cooling or heating setpoint temperature in case of intermittent thermostat setpoints. Such prolonged preheating or precooling periods in buildings with large thermal inertia could result in additional energy expenditures or extended periods of discomfort for the occupants [2]-[4].

This paper explores the net contributions of building thermal mass on heating energy consumption of a semidetached dwelling in a temperate heating-dominated climate, and investigates this in relation to occupancy profiles and thermostat settings.

\section{Quantifying thermal mass impacts}

In literature, many studies report on the impacts of thermal inertia in buildings, but their findings vary greatly amongst authors. While there is nearly a consensus about the comfort benefits of high mass

\footnotetext{
* Corresponding author: stijn.verbeke@uantwerpen.be
} 
buildings with respect to summer overheating risks, the reports on heating energy impact vary greatly. Major influencing factors attributing to this difference in reported relative impacts of thermal inertia are to be found in differences in research methods and in the considered boundary conditions such as climatic conditions and the building occupancy profiles [5]. Many studies on thermal inertia are restricted to the analysis of individual building components and don't factor in the intricate thermodynamic processes within a room or a building as a whole. Furthermore, boundary conditions are often highly simplified, e.g. by assuming sinusoidal temperature fluctuations in standard EN ISO 13786:2007 [6].

For a detailed analysis of the thermal mass contributions to a building design, dynamic whole building energy performance simulation (BEPS) tools are the most suitable instrument. Such software allows designers, engineers and researchers to model the dynamic behaviour of the building and its composing systems in great detail. Dynamic simulation tools explicitly take into account material properties which define the transient behaviour, such as the density $\rho$ and specific heat capacity $\mathrm{c}$ of the material which define the amount of heat that can be stored, and the thermal conductivity $\lambda$ which influences the rate of heat exchange.

Simplified (quasi) steady-state calculation tools on the other hand are not able to directly quantify the dynamic effects of the heat flow, storage and release. Although such tools lack many of the capabilities of advanced dynamic simulation software, they are more commonly used in today's architectural design practice, especially for small scale projects such as individual dwellings. They are straightforward to understand and communicate and require less time and expert knowledge compared to more advanced building energy modelling tools [7], [8]. European standard EN ISO 52016-1 introduces a gain-utilisation factor to encompass dynamic effects in simplified (quasi) steadystate calculation methods with monthly heat balances [9]. This factor expresses that not all 'free' heat gains will be useful for reducing the heat demand. This method is widely used in the national certification schemes, implementing the European Energy Performance of Buildings Directive. Using such heat gain-utilisation factor, the heating demand of a building will slightly reduce for buildings with a higher time-constant, hence more exposed thermal mass.

\section{Research methods}

This study sets out to explore the impacts of thermal mass in dwellings. Measuring such impacts would not be a straightforward undertaking: the effect is expected to be relatively small, and in real life situations it would be very hard to solely vary the thermal mass of construction components while fixing all other material properties, boundary conditions and occupant behaviour. Therefore, it was opted to use a simulation study instead.

\subsection{Building model}

In this work, the dynamic BEPS software EnergyPlus version 8.7.0.is used to model the energy performance of the buildings under study. The analysis covers the heating energy demand for a full year with a three minute time step. By default, this software uses Conduction Transfer Functions (CTF) to solve the differential equations describing the heat transfer. In this work however, it was opted to deploy the optional Conduction Finite Difference model. Although this model is more calculation time intensive, it allows to explicitly simulate energy flows and temperatures at multiple nodes of the opaque construction assemblies and thus incorporate the thermal inertia effects in greater detail [10]. A virtual model of a semi-detached residential building was developed. This house is modelled consisting of eight interlinked thermal zones, which corresponds to individual rooms: kitchen, living room, bathroom, 3 distinct bedrooms, an unheated attic and "auxiliary zone" containing corridor, storage space and stairs (see figure 1). Within a thermal zone, the air is supposed to be perfectly mixed and thus uniform in temperature. Further simplifications used in this BEPS model include the restriction to one-dimensional heat transfer in construction components and a simplified model of the heating system. This heating system is modelled as an ideally controlled radiant-convective electric system, hence does not take into account the thermal inertia of a hydronic system. Climate data from the 'International Weather for Energy Calculations' (IWEC) climate file for Uccle (Brussels, WMO Station 064510) are used in all simulations.
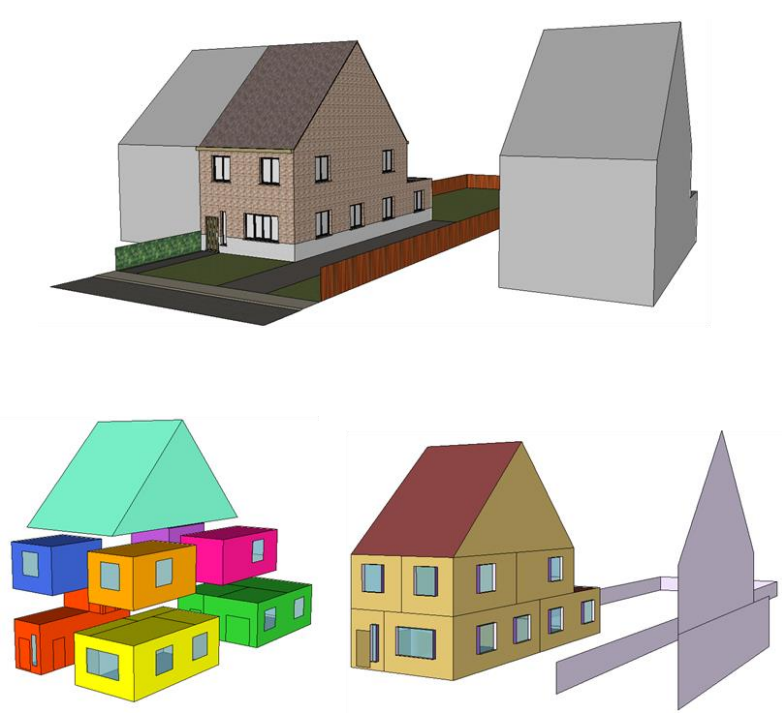

Fig. 1. Geometric model of the semi-detached dwelling. The model incorporated eight interconnected thermal zones and external shadow casting elements.

For the opaque external constructions, 5 variations of thermal resistance are defined: R1, R2, R3, R5 and R10. The layers are identical except for the thickness of the 
thermal insulation layers, which is varied so the onedimensional total thermal resistance of all layers equals $1.0 \mathrm{~m}^{2} \mathrm{~K} / \mathrm{W}, 2.0 \mathrm{~m}^{2} \mathrm{~K} / \mathrm{W}, \quad 3.0 \mathrm{~m}^{2} \mathrm{~K} / \mathrm{W}, \quad 5.0 \mathrm{~m}^{2} \mathrm{~K} / \mathrm{W}$ respectively $10 \mathrm{~m}^{2} \mathrm{~K} / \mathrm{W}$. This covers the range from hardly insulated constructions $( \pm 0.015 \mathrm{~m}$ of wall insulation) to constructions exceeding the insulation values suggested for reaching the Passive House standard.

\subsection{Thermostat setpoints}

Two sets of thermostat setpoint schedules have been considered for the heating system: (a) a fixed thermostat setpoint without daytime of night-time setbacks of $20^{\circ} \mathrm{C}$ in the living room and kitchen, $24^{\circ} \mathrm{C}$ in the bathroom and $15^{\circ} \mathrm{C}$ in the bedrooms and auxiliary zones; and (b) an intermittent setpoint schedule which introduces thermostat setbacks to $16^{\circ} \mathrm{C}$ during the night and during working days when the building is not occupied. The temperature settings during the occupied hours are equal to those defined for schedule (a).

On top of the two thermostat regimes, two modelling approaches have been deployed for the thermostat control: a traditional air temperature based thermostat and an operative temperature based thermostat model. The operative temperature is defined as the arithmetic mean of zone air temperature and zone mean radiant temperature. Operative temperature is closely related to the thermal comfort sensed by an occupant [11].

The benefit of this approach is that all variants are treated based on an equal thermal comfort level, unlike the situations in which the air temperature based thermostat solely keeps the air temperatures between different buildings identical, but for which the mean radiant temperatures might differ. For the building variants considered, the variations in surface temperature can be caused by variations in thermal insulation as well as by differing thermal mass properties.

Under steady-state winter conditions, the internal surface temperature of an outdoor wall, ceiling or floor will be slightly lower if the thermal insulation is lower. This effect is due to the relatively higher share of the surface heat transfer component in the overall thermal resistance. Such lower surface temperature would lead to lower comfort sensations during heating season. Occupants can compensate for this by demanding a slightly higher air temperature compared to a similar well insulated building, in order to overcome the lower radiant temperatures. Apart from the thermal insulation effects, the thermal mass of the building components can also affect the comfort sensations of the occupants due to differences in radiant temperature. The thermal inertia of a building will generally cause it to react slower on a change in environmental boundary conditions. In case the room thermostat imposes an intermittent heating profile, switching on the heating system will lead to a raise in indoor air temperature. As a result building construction elements facing the room will also start heating up. The temperature regimes in a heavy and lightweight alternative of a similar building can differ, even with an 'ideal' heater with no capacity limit as depicted in the simulation results of figure 2. The air temperature might be the same in both cases, but the surface temperatures (here referenced by the 'mean radiant temperature' of the zone) effectively raise slower for the building with a heavy mass structure compared to a building with less thermal inertia. To some extent, this can also influence the heating demand of a building. Based on their experience of the temperature regime in a building, the occupants might alter the timing and temperature settings of a programmable thermostat to anticipate on potential discomfort. By using an idealized thermostat control based on operative temperatures, the same level of thermal comfort is imposed for all building variants. This creates a 'level playing field' to compare building variants (see figure 3 ).

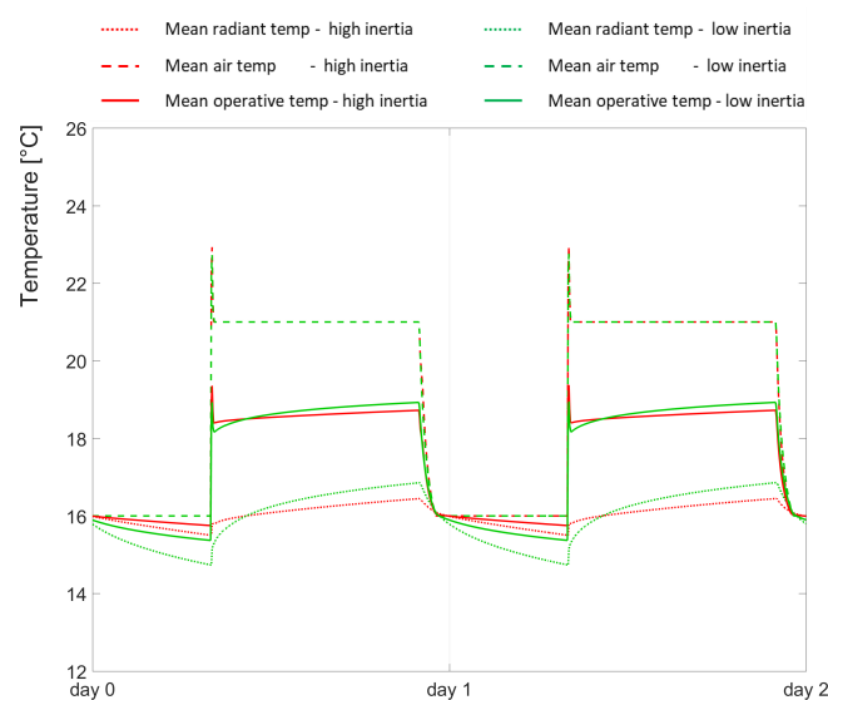

Fig. 2. Ideal air heater with air temperature based thermostat regime with night set-back and artificial steady-state outdoor conditions - R1 insulated building without windows. The short peaks at the beginning of each ramp-up are caused by control instabilities in the simulation

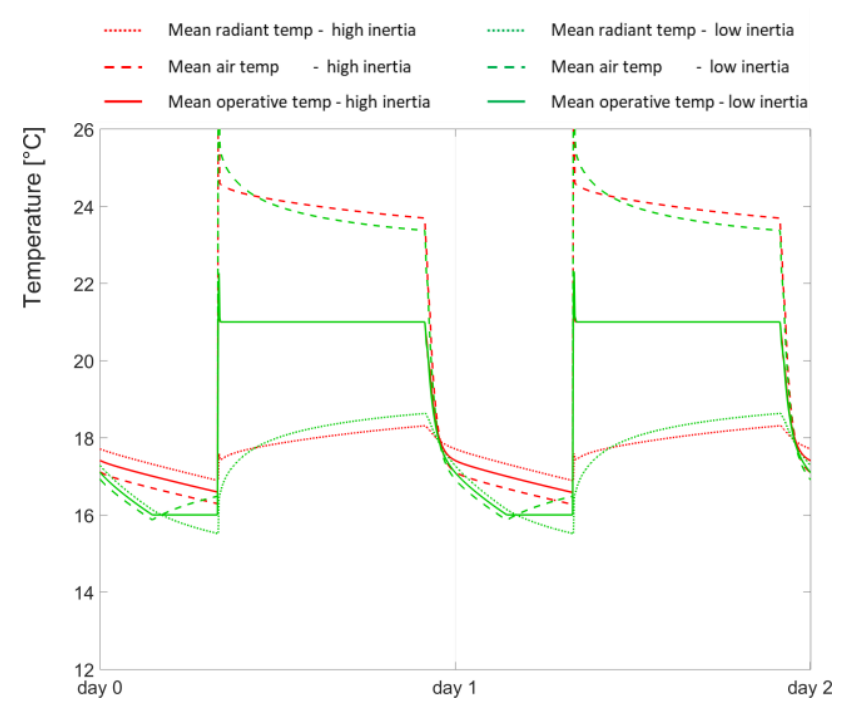

Fig. 3. Ideal air heater with operative temperature based thermostat regime with night set-back and artificial steady-state outdoor conditions - R1 insulated building without windows. 
If the actual room thermostat sensors would only capture dry bulb air temperature, the operative thermostat control would be a highly hypothetical control mode, requiring a continuous variation of air temperature setpoints in order to reach a predefined operative temperature for each room. Lomas and Porrit [12] however point out that actual thermostat sensors measure an undefined mix of air and radiant temperatures, with possibly a component of surface temperature at the mounting place. They conclude that this can result in the recording of a temperature which is closer to the operative temperature sensed by occupants than the dry-bulb air temperature. Nevertheless, in reality the thermostat control implemented by occupants will probably not correspond to the simple air temperature based thermostat nor the operative thermostat, but rather come down to a combination of adjustments to thermostat temperature setpoints, thermostat timing schedules and some comfort tradeoffs. In this work, both idealized air temperature based control and operative control will be implemented and compared.

\subsection{Sizing of the heating systems}

In order to size the heating units in each zone, the methodology of ISO EN 12831:2003 [13] and national addendum prNBN EN 12831:2014 is used. A winter design temperature of $-8^{\circ} \mathrm{C}$ is assumed and solar and internal heat gains are neglected during the sizing calculation. The additional power demand for heating-up during intermittent use is calculated using the assumptions of a temperature drop of $2^{\circ} \mathrm{C}$ and a reheat time of two hours. In deviation from the default approach, the sizing calculations are performed with the assumption that the neighbouring rooms are conditioned at their setback temperatures. Using these calculated heating systems capacities in the EnergyPlus simulations, revealed that the heating system lacks power for heating up the bathroom in an acceptable amount of time. Therefore, the sizing assumptions where adapted to include a $4^{\circ} \mathrm{C}$ drop and two hour reheat time for the bathroom instead.

Table 1. Calculated required room heating capacities for semidetached dwellings with R1 and R10 insulation with intermittent heating schedule.

\begin{tabular}{|c|c|c|}
\hline Room & $\begin{array}{c}\text { Sized heating } \\
\text { capacity [W] for } \\
\text { R1 insulation }\end{array}$ & $\begin{array}{c}\text { Sized heating } \\
\text { capacity [W] for } \\
\text { R10 insulation }\end{array}$ \\
\hline Living room & 5550 & 3300 \\
\hline Kitchen & 3800 & 2500 \\
\hline Hall & 0 & 0 \\
\hline Bedroom1 & 750 & 550 \\
\hline Bedroom2 & 1150 & 900 \\
\hline Bedroom3 & 1150 & 550 \\
\hline Bathroom & 3500 & 2850 \\
\hline Sum & $\mathbf{1 5 9 0 0}$ & $\mathbf{1 0 6 5 0}$ \\
\hline
\end{tabular}

Table 1 presents the results for the two most extreme cases. Despite the considerable better thermal insulation of the R10 variant, the heating capacity remains at two thirds of the R1 variant because of the significant power demand for ramping up the temperature after the thermostat setback period.

Because of the limited capacity of the heating systems, a period of heating-up can be observed before the zone reaches its desired temperature as set by the thermostat. The duration of this period depends on multiple parameters, such as the installed capacities, the thermal insulation of the building envelope, the thermal mass of the constructions, and the indoor and external temperatures of the zone and its neighbouring zones.

In anticipation of this behaviour, occupants can program their thermostat to start the heating prior to the actual occupation. Contemporary 'smart', or 'selflearning' thermostats will estimate the optimum timing based on analytics of former behaviour, sometimes enriched with weather data predictions or connections with smartphones or agendas of the occupants [14]. In this work however, a common more simple programmable thermostat with fixed daily or weekly schedules is considered more representative for the buildings with intermittent heating profiles.

Although occupants could alter the settings when they deem fit, the literature reviews by Peffer et al. [15] and Meier et al. [16] indicate that only a small minority of occupants will actually undertake any action to revise thermostat schedules after initially programming the settings. In this work, it is therefore assumed that the heating profile will be defined by one single relatively cold winter day. For this design day, the time needed to reach the thermostat setpoint temperature is calculated from the EnergyPlus simulations. The design day chosen, is not the coldest day of the year. Occupants will likely display some laziness and not alter the thermostat program after one single very cold day in which the room did not reach the intended temperature at the requested time. If this occurs more often, the urge to alter the settings will become more apparent. In this work, the $98 \%$ percentile of the ambient temperature at 7 $\mathrm{AM}$ was chosen as the ambient design temperature. This equals $-2.9^{\circ} \mathrm{C}$ for the Uccle climate file.

\section{Results and discussion}

\subsection{Start-up time of a capacity limited heating system}

Figure 4 displays the resulting temperature profile for a cold winter day in a heavyweight limestone and concrete construction, while figure 5 provides a similar analysis for a lightweight timber frame construction. Comparing both figures, it can be observed that the required preheating time is not necessarily shorter for lightweight buildings. The thermal inertia effect causes a delay in heating up the building, but in a similar fashion also slows down the temperature decay during the night. 

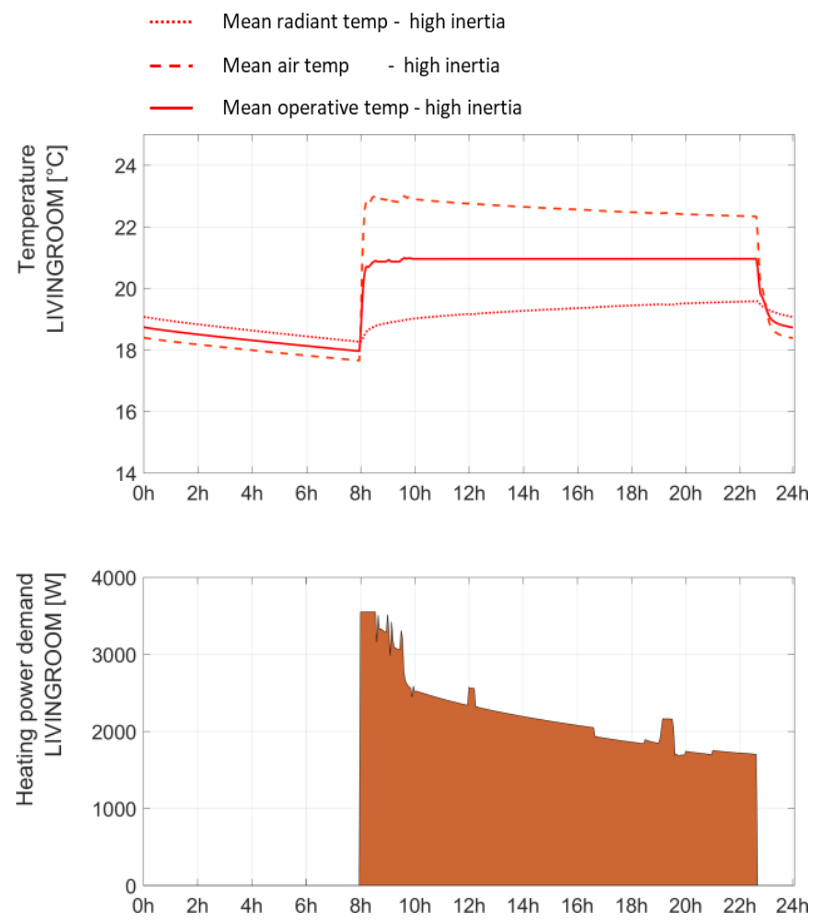

Fig. 4. Temperature and power demand of capacity limited HVAC system for living room of heavyweight R5 building

Both the radiant and air temperature show a much more expressed decline during temperature set-back periods in the lightweight construction. For the cases displayed, an operative zone temperature at the beginning of the heating cycle of $\theta_{\mathrm{OP}}=18.0^{\circ} \mathrm{C}$ is found for the heavyweight variant versus $\theta_{\mathrm{OP}}=15.2^{\circ} \mathrm{C}$ for the lightweight variant. Given equal system capacities, the lower initial temperature causes a longer start-up period for the lightweight building in this particular case.

The required pre-heating period is also dependent on the level of the thermal insulation of the building enveloppe. For the heavyweight constructions with operative thermostat control, an average heating-up time of 75 minutes is found for the poorly insulated R1 variants, whereas for well-insulated R10 cases this period reduces to 35 minutes despite lower installed capacities. For lightweight constructions, the required time is less dependent on the thermal insulation, with a mean timing of 72.6 minutes (standard deviation over the five insulation categories equals 6.8 minutes).

Since the thermal capacity of the body of air is low, the resulting pre-heating period is much shorter in case only air temperature is considered in the thermostat control. With the identical heating capacities as the previous case, the average heating-up period is reduced to 20 minutes for the heavyweight $\mathrm{R} 1$ case and 7 minutes for the well-insulated R10 case. The lightweight constructions require 16 minutes for the $\mathrm{R} 1$ case and 21 minutes for the R10 case. This difference is mainly to be attributed to the differences in sizing of the heat emitters.
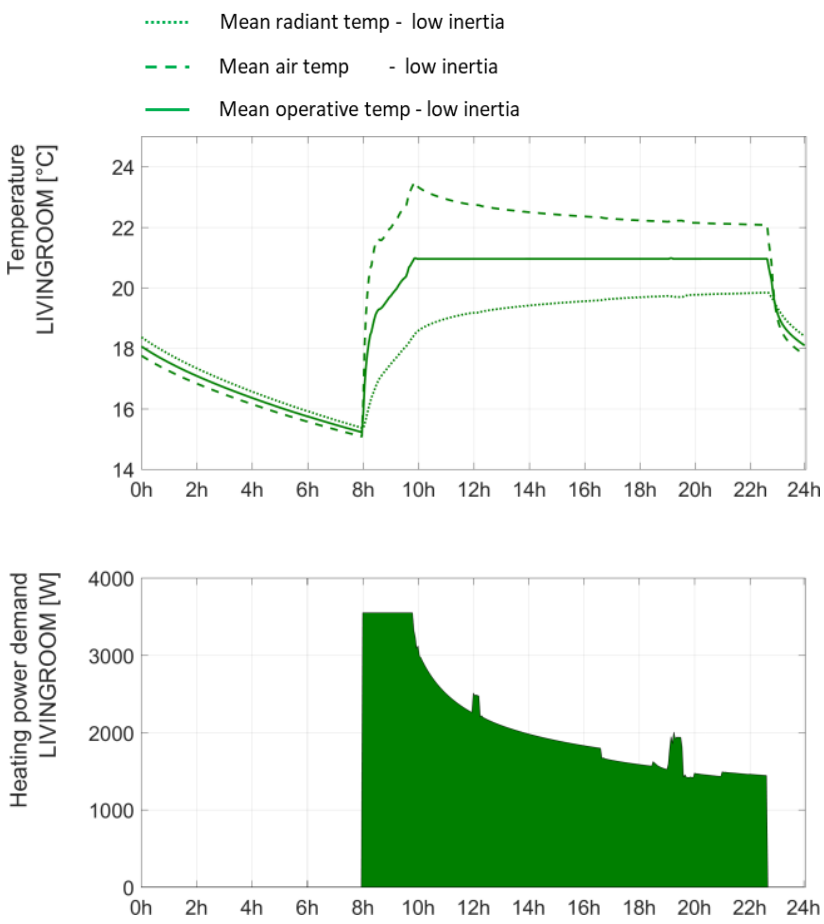

Fig. 5. Temperature and power demand of capacity limited HVAC system for living room of lightweight R5 building

\subsection{Idealised system with unlimited capacity system and operative temperate control}

EnergyPlus simulations are carried out to assess the annual heat energy demand of the semi-detached buildings with various degrees of thermal insulation of the building envelope and two variations of construction thermal mass. The simulations span a full year and are conducted with a three-minute time step. In first instance, idealised heaters are considered with unlimited capacity. In Table 2 the processed results of the simulation runs are depicted; displaying the relative differences in annual heating energy demand when switching from a heavy mass construction to a lightweight timber frame dwelling while fixing all other design parameters.

Table 2. Relative changes in annual energy demand $\Delta E_{\text {heat,yr }}$ when switching construction inertia type of the semi-detached dwelling for 5 distinct envelope insulation levels.

\begin{tabular}{|c|c|c|}
\cline { 2 - 3 } \multicolumn{1}{c|}{} & \multicolumn{2}{c|}{$\Delta \mathbf{E}_{\text {heat,yr, Heavyweight } \rightarrow \text { Lightweight }}$} \\
\hline $\begin{array}{c}\text { Enveloppe } \\
\text { insulation }\end{array}$ & $\begin{array}{c}\text { Ideal HVAC }- \\
\text { constant setpoint - } \\
\text { operative temp }\end{array}$ & $\begin{array}{c}\text { Ideal HVAC - } \\
\text { Intermittent setpoint- } \\
\text { operative temp }\end{array}$ \\
\hline R1 & $+4.3 \%$ & $-3.3 \%$ \\
\hline R2 & $+3.8 \%$ & $-4.5 \%$ \\
\hline R3 & $+4.3 \%$ & $-4.4 \%$ \\
\hline R5 & $+5.0 \%$ & $-3.7 \%$ \\
\hline R10 & $+6.6 \%$ & $-2.3 \%$ \\
\hline Average & $+\mathbf{4 . 8} \%$ & $-\mathbf{3 . 6} \%$ \\
\hline
\end{tabular}


The results indicate that in case of a fixed thermostat profile, a reduction of the thermal mass of the construction can lead to an increase of the heating energy consumption. On average, an additional energy expenditure of $4.80 \%$ can be noticed. For the best insulated R10 case study building variant, the absolute rise of the energy demand is small, but in relative terms this consists of an increase of $6.60 \%$ of the annual space heating demand. The lower energy consumption of the heavy mass constructions can be explained by their ability to better store heat gains from occupants and their activities and solar gains. Contrary to lightweight buildings, a large amount of heat gains will not directly lead to higher indoor temperatures, hence more elevated ventilation and conduction losses.

Next to a fixed thermostat setpoint, an occupancy pattern of a 4 person family implementing a thermostat with set-back regime during nights and during absence on working days is also modelled. Under these assumptions, the heavy constructions display a slightly higher heating energy consumption compared to the timber frame constructions with a low level of thermal inertia but identical steady state thermal resistances. On average, the yearly heating energy demand will then reduce by $3.60 \%$ when switching to the lightweight timber frame construction method.

The lower energy demand for intermittently heated buildings can be explained by their faster cool down. The average temperature difference with their surroundings will thus be lower during the set-back regime, which reduces the energy losses by conduction, ventilation and air-infiltration during unheated periods. This effect is often neglected in simplified calculation methods. For the case study buildings under investigation, such effects appear to be more important than the reduced capacity to store heat gains, resulting in a net benefit for low mass constructions in case of intermittent heating patterns.

It can be noted that overall the effect of thermal inertia on the yearly heating energy consumption is relatively moderate for dwellings in the temperate Belgian maritime climate. With an order of magnitude of a few percent deviations depending on the thermal mass, this factor is less influential on the heating energy demand than other design characteristics such as thermal insulation, window size and glazing properties. Furthermore, the impacts on heating energy demand can be opposite depending on the thermostat schedule implemented by the occupants. Adjusting the thermal mass of the constructions is thus not a robust design strategy for the dwellings under investigation. Apart from annual heating energy demand, the thermal inertia effects could also affect summer overheating risks and resulting cooling energy demands. If total system efficiency is considered, the thermal mass effects could also contribute to lower carbon emissions of the heating system, for example by allowing demand-response regimes in a smart grid context [17]. These additional elements are however not taken up in the scope of this paper which limits the analysis to the net heating energy demand.

\subsection{Capacity limited systems with intermittent operative temperature thermostat control}

In order to investigate a more realistic scenario, a heat delivery capacity limit is now introduced. To enable a fair comparison of all cases, the thermostat schedules are adapted by shifting the start-up of the heating in the morning forward with the time required to heat up the building for a particular design day (see 3.1). This preconditioning phase is dependent on the thermal mass of the construction and thermal insulation of the envelope. As a result of the capacity limited and adjusted timing, the annual energy consumption of the buildings increases compared to the idealised systems discussed in section 3.2. On average an increase of $17.9 \%$ of the heating energy demand is found (see Table 3 ).

Table 3. Relative changes in annual energy demand $\Delta E_{\text {heat,yr }}$ when switching from idealised HVAC system to capacitylimited system with adjusted ramp-up times in the semidetached dwelling for 5 distinct envelope insulation levels.

\begin{tabular}{|c|c|c|}
\cline { 2 - 3 } \multicolumn{1}{c|}{} & \multicolumn{2}{c|}{$\begin{array}{c}\Delta \mathbf{E}_{\text {heat,yr Idealised } \rightarrow \text { Capacity-limited }} \\
\text { (Intermittent thermostat, operative } \\
\text { temperature controlled) }\end{array}$} \\
\hline $\begin{array}{c}\text { Enveloppe } \\
\text { insulation }\end{array}$ & $\begin{array}{l}\text { Heavyweight } \\
\text { construction type }\end{array}$ & $\begin{array}{l}\text { Lightweight } \\
\text { construction type }\end{array}$ \\
\hline R1 & $+22.7 \%$ & $+15.9 \%$ \\
\hline R2 & $+20.7 \%$ & $+18.4 \%$ \\
\hline R3 & $+18.4 \%$ & $+18.9 \%$ \\
\hline R5 & $+15.5 \%$ & $+17.9 \%$ \\
\hline R10 & $+13.9 \%$ & $+16.3 \%$ \\
\hline Average & $\mathbf{1 8 . 2 \%}$ & $+\mathbf{1 7 . 5 \%}$ \\
\hline
\end{tabular}

In turn, the relative impact of the thermal inertia effects is also impacted by introducing the more realistic assumptions on heating system capacity and start-up time. Most rooms of the lightweight constructions displayed an earlier start-up compared to the heavyweight constructions. Once the desired temperature is reached, the remaining power demand is however lower. For the cases investigated, the combination of both effects still results in a net reduction of the annual heating energy demand for constructions with low thermal inertia, as depicted in the second column of Table 4. Although the average effect is equal to the ideal system with intermittent control as listed in Table 2, the thermal inertia effects appear to be much more pronounced for poorly insulated buildings, compared to highly insulated alternatives.

\subsection{Capacity limited systems with intermittent air temperature thermostat control}

Finally, the analysis in 3.2 is repeated with thermostats controlled by the mean air temperature in the zone instead of the previously discussed operative control. Since the thermal capacity of the body of air is low, the resulting pre-heating period is much shorter for the air 
temperature controlled operation. With the altered preheating schedule in place, the air-temperature-controlled variants display on average a $24 \%$ lower heating energy consumption compared to those with operative temperature control. Such reduction is expected, since in the intermittent heating regime, the air temperature in the buildings with operative temperature control will often need to rise higher to compensate for the lower mean radiant temperatures of the surrounding surfaces to reach the desired operative temperature level.

Table 4. Relative changes in annual energy demand $\Delta E_{\text {heat,yr }}$ when switching construction inertia type of the semi-detached dwelling for 5 distinct envelope insulation levels.

\begin{tabular}{|c|c|c|}
\cline { 2 - 3 } \multicolumn{1}{c|}{} & \multicolumn{2}{c|}{$\Delta \mathbf{E}_{\text {heat,yr Heavyweight } \rightarrow \text { Lightweight }}$} \\
\hline $\begin{array}{c}\text { Enveloppe } \\
\text { insulation }\end{array}$ & $\begin{array}{c}\text { Capacity limited - } \\
\text { Intermittent setpoint- } \\
\text { operative temp }\end{array}$ & $\begin{array}{c}\text { Capacity limited - } \\
\text { Intermittent setpoint- } \\
\text { air temp }\end{array}$ \\
\hline R1 & $-7.5 \%$ & $-3.1 \%$ \\
\hline R2 & $-5.3 \%$ & $-3.2 \%$ \\
\hline R3 & $-3.5 \%$ & $-3.9 \%$ \\
\hline R5 & $-1.4 \%$ & $-2.2 \%$ \\
\hline R10 & $-0.2 \%$ & $-0.1 \%$ \\
\hline Average & $\mathbf{- 3 . 6 \%}$ & $\mathbf{- 2 . 5 \%}$ \\
\hline
\end{tabular}

The last column of Table 4 displays the relative thermal inertia effects for buildings with air temperature controlled thermostats. The impacts of thermal mass are generally less expressed compared to the alternative operative temperature control. A variant without capacity limit or preheating was also tested. In this case, the lightweight constructions can even have a slightly higher energy demand at the low R1 insulation levels $(+1.2 \%$ compared to heavyweight alternative). This is in deviation of the prior findings on the case of intermittently heated buildings. It is stressed however that under this type of thermostat control, differences in thermal comfort will arise during winter season. The comparison between building variants is in this case thus slightly biased and the reported differences in heating energy demand need to be traded off with variations in occupant thermal sensations.

\section{Conclusions}

This research paper investigates thermal inertia effects in a semi-detached dwelling located in the moderate Belgian climate using the EnergyPlus simulation software with the detailed Conduction Finite Difference model.

A thermostat scheme based on sensing operative temperature is used for most simulations, as this ensures comparing building variants which will deliver the same global thermal comfort experience to the occupants. In case an idealised HVAC system with a fixed thermostat setpoint and without capacity limits is assumed, a timber frame construction with low levels of thermal mass will on average yield a $+4.80 \%$ higher annual heating demand compared to a heavy weight construction with the same steady-state thermal conductance. In contrast, if a thermostat schedule with a temperature setback regime is implemented, the lightweight constructions will have a slightly lower energy demand compared to the heavyweight constructions. The average energy demand reduction over the five thermal insulation categories investigated is $-3.6 \%$.

Next, a more realistic HVAC system with capacity limited and adjusted timing for the temperature ramp-up phase of the intermittent thermostat schedule is investigated. The thermal inertia of construction materials will not only delay the heating up of the building, but also limit the temperature drop during the night time set-back. For most cases investigated, this results in a longer start-up period for the timber frame buildings. When implementing such adjusted timing so all buildings deliver similar comfort conditions, the heating energy demand increases on average with $17.9 \%$.

This in turn affects the predicted impact of the building thermal mass: in the assumed operative temperature control regime the lightweight dwellings use on average $3.6 \%$ less energy - as was the case with the idealised systems - but for the poorly insulated building types the relative difference is larger; up to $-7.5 \%$ of the annual energy demand. A system managed by an air temperature thermostat control would result on average in $-2.5 \%$ energy savings for the intermittently heated lightweight construction, but also in this case the differences between heavy mass and lightweight buildings are far less expressed for the well-insulated building variants.

It can be concluded that simplified heat balance methods are not sufficiently capable of capturing the complex reality of heat storage and transient flows in building materials. Detailed dynamic simulations reveal that the energy saving potential is strongly depended on the thermostat control schedule implemented by the occupants, and for the cases and boundary conditions analysed, lightweight constructions might be favoured over thermally inert buildings in case of intermittent heating schedules. The absolute contribution of the thermal inertia effects on the yearly heating energy demand is limited, and since the effects are dependent on the occupancy profiles, it cannot be considered as a robust energy efficiency measure to reduce the heating demand.

\section{References}

1. G. John, D. Clements-Croome, G. Jeronimidis, "Sustainable building solutions: A review of lessons from the natural world," Build. Environ., 40, no. 3 (2005)

2. K. Miura, "The Analysis of a Thermal Storage System utilizing Building Mass in a Cold Region," Proceedings Building simulation 2007. (2007) 
3. J. Karlsson, L. Wadsö, M. Öberg, “A conceptual model that simulates the influence of thermal inertia in building structures," Energy Build., 60, (2013)

4. P. Hoes, M. Trcka, J. L. M. Hensen, B. Hoekstra Bonnema, "Investigating the potential of a novel low-energy house concept with hybrid adaptable thermal storage," Energy Convers. Manag., 52, 6, pp. 2442-2447 (2011)

5. S. Verbeke, A. Audenaert, "Thermal inertia in buildings: A review of impacts across climate and building use," 82, no. 3, Renew. Sustain. Energy Rev., (2018)

6. CEN, "EN ISO 13786: 2007, Thermal performance of building components - dynamic thermal characteristics - calculation method." (2007)

7. S. Attia, J. L. M. Hensen, L. Beltrán, A. De Herde, "Selection criteria for building performance simulation tools: contrasting architects' and engineers' needs," J. Build. Perform. Simul., 5, no. 3, (2012)

8. S. Petersen, S. Svendsen, "Method and simulation program informed decisions in the early stages of building design," Energy Build., 42, no. 7, (2010)

9. CEN, "EN ISO 52016-1:2017: Energy performance of buildings - Energy needs for heating and cooling, internal temperatures and sensible and latent heat loads -- Part 1: Calculation procedures." (2017)

10. P. C. Tabares-Velasco, C. Christensen, M. Bianchi, C. Booten, "Verification and Validation of EnergyPlus Conduction Finite Difference and Phase Change Material Models for Opaque Wall Assemblies," Technical Report NREL/TP-550055792, Denver, Colorado, (2012)

11. F. M. Butera, "Chapter 3 - Principles of thermal comfort, Politecnico di Milano," Renew. Sustain. Energy Rev., 2, (1998)

12. K. J. Lomas, S. M. Porritt, "Overheating in buildings: lessons from research," Build. Res. Inf., 45, no. 1-2, (2017)

13. CEN. EN, "EN 12831: 2013 - Heating systems in buildings. Method for calculation of the design heat load." EN ISO (2003)

14. R. Yang, M. W. Newman, "Learning from a Learning Thermostat: Lessons for Intelligent Systems for the Home," Proc. 2013 ACM Int. Jt. Conf. Pervasive ubiquitous Comput., (2013)

15. T. Peffer, M. Pritoni, A. Meier, C. Aragon, D. Perry, "How people use thermostats in homes: A review," Build. Environ., 46, no. 12 (2011)

16. A. Meier et al., "How People Actually Use Thermostats," Control. Inf. Technol., (2010)

17. G. Reynders, T. Nuytten, D. Saelens, "Potential of structural thermal mass for demand-side management in dwellings," Build. Environ., 64, (2013) 